\title{
Case of Self Inflicted Injury with A Broken Needle in the Interdental Area
}

Vidyavathi H Patil' ${ }^{1}$ Prachi J ayesh Thakkar², Chaitanya Uppin ${ }^{3}$, Shivayogi M Hugar ${ }^{4}$

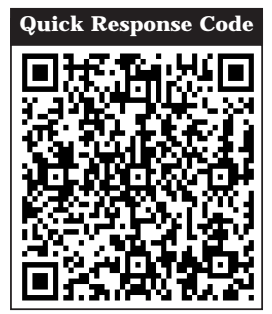

doi: 10.5866/2015.7.10204

1\&3Senior Lecturer

2Post graduate Student

${ }^{4}$ Professor

Department of Pedodontics and Preventive dentistry, KLE VK Institute of Dental Sciences,

KLE University, Belagavi.

\section{Article Info:}

Received: J uly 9, 2015

Review Completed: August 7, 2015

Accepted: September 8, 2015

Available Online: J uly, 2015 (www.nacd.in)

(c) NAD, 2015 - All rights reserved

\section{Email for correspondence:}

nisarga_vhp@yahoo.com

\section{ABSTRACT:}

A foreign body in the oral cavity is usually associated with an accidental aetiology or habits which may lead to discomfort and infection to the patient. Timely management is necessary to overcome these problems. We present a case which describes a successful retrieval of a needle lodged in the interdental area.

Key words: foreign body, habits, management.

\section{NTRODUCTION}

Self injurious behaviour is the deliberate alteration to one's own body part without suicidal intent. ${ }^{1,2}$ Self inflicted injuries are common and can range from simple to severe forms of mutilation. Many foreign objects are reported to be lodged in the oral cavity like darning needles, pencil leads, metal screws, stapler pins and beads. ${ }^{3}$ Diagnosis of foreign bodies in the oral cavity is usually accidental on clinical or radiographic examination and is usually associated with infection, pain and swelling. ${ }^{3-5}$
It becomes necessary to obtain a detailed case history along with clinical and radiographic examinations to ascertain exact location, size, nature of the foreign body and difficulty encountered while retrieving the foreign body. The present case describes the retrieval of a broken sewing needle from interdental area of teeth 74 and 75 .

\section{CASE REPORT}

A 12 years old asian girl presented to the Department Of Pedodontics And Preventive Dentistry with a chief complaint of pain and food lodgement in the lower left back region of jaw since 


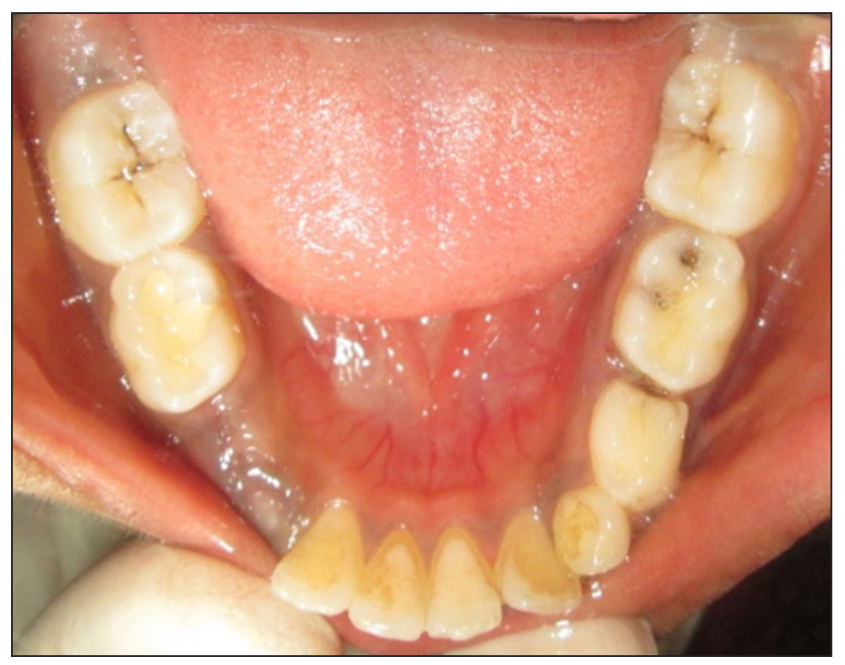

Figure 1: Mandibular arch showing distal caries with 74 and occlusal caries with 75 .

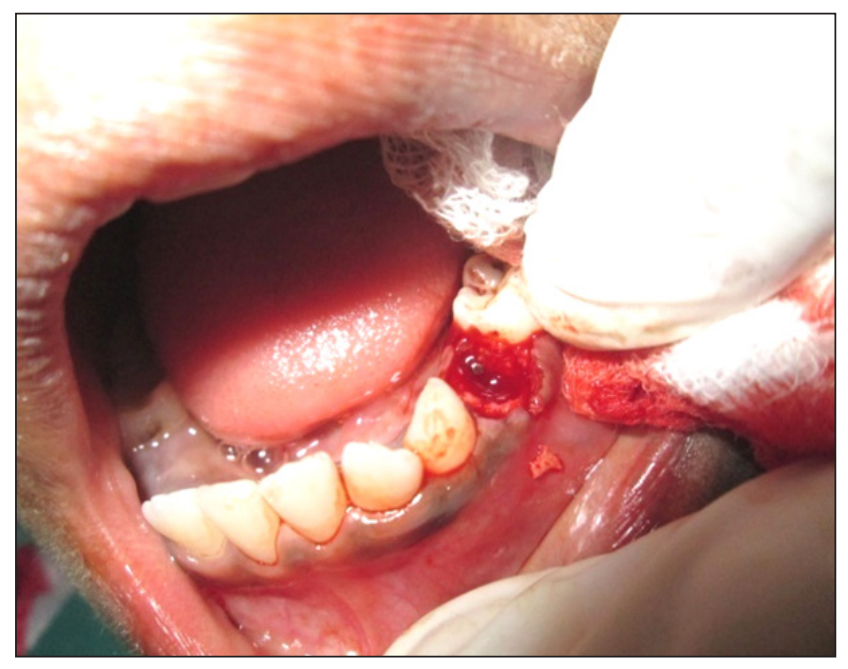

Figure 3: Needle fragment visible after extraction of tooth 74.

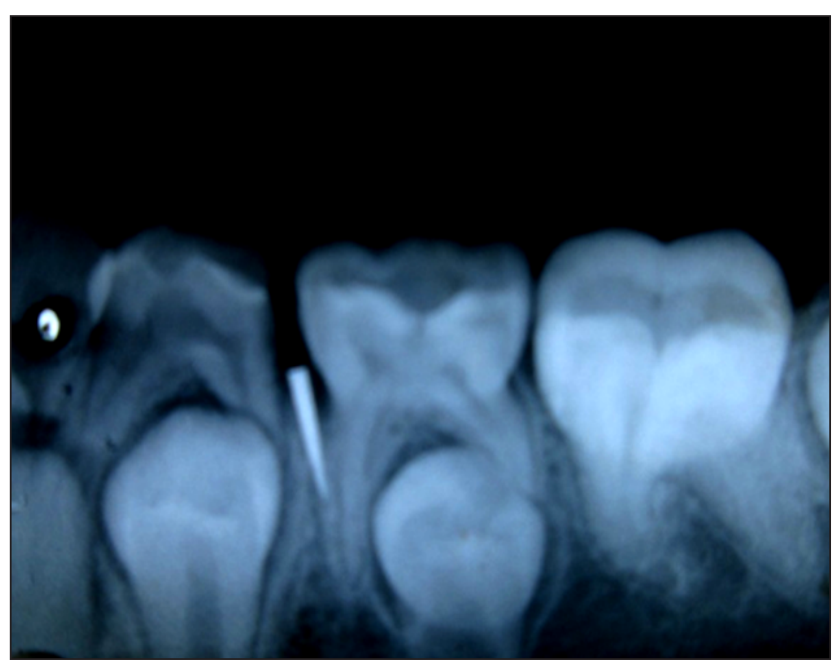

Figure 2: IOPA showing radio opaque object in the interdental area between tooth 74 and 75 .

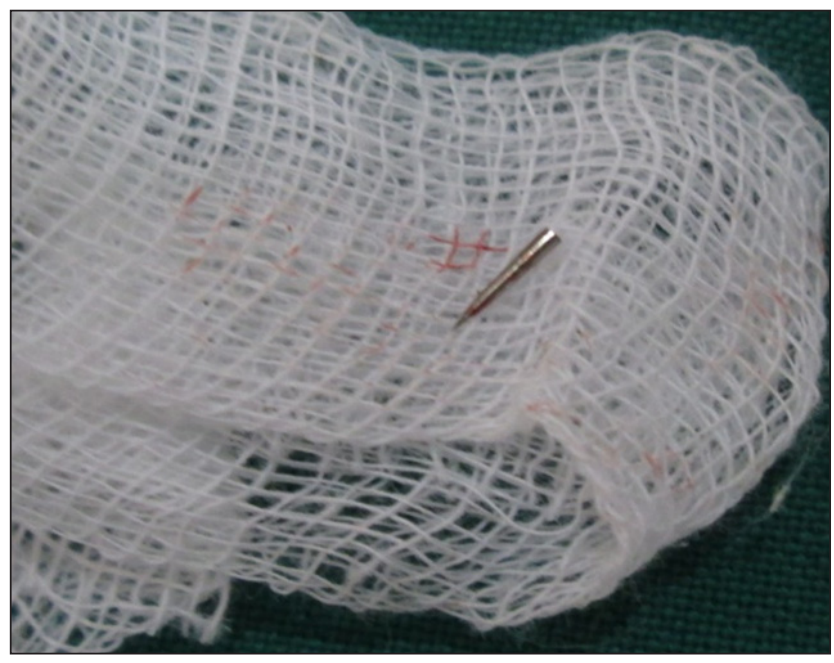

Figure 4: Needle fragment after retrival.

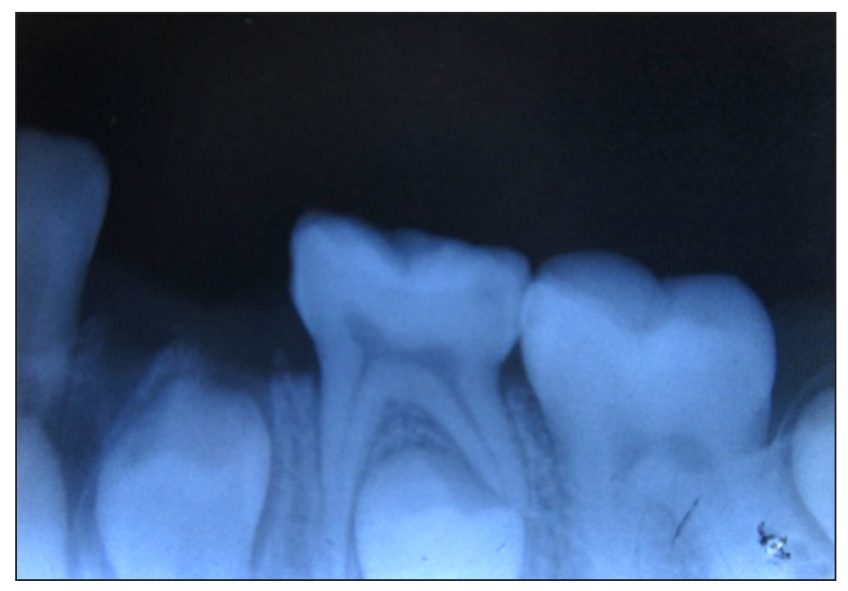

Figure 5: Post extraction IOPA 
7 days. Intraoral examination revealed a proximal carious lesion involving the distal surface of tooth 74 and occlusal caries with 75 (Figure 1). The soft tissue in the interdental area appeared normal. An intraoral periapical radiograph was advised which revealed the presence of a sharp radiopaque object present in relation to the interdental area between tooth 74 and 75 (Figure 2). On further questioning the child revealed to have used a needle which had broken in an attempt to take out the impacted food.

The procedure was explained to the child and parent; and informed consent was obtained. Extraction of tooth $\# 74$ was carried out under local anaesthesia. This provided vision and accessibility for the retrival of the broken needle from the interdental area (Figure 3). On removal, the fragment measured approximately $8 \mathrm{~mm}$ in length (Figure 4). A post operative radiograph was taken to evaluatethecomplete removal (Figure 5). The patient was followed up a week later when clinical examination reveal ed adequate healing and absence of any pathology. Space maintainer was not planned for this patient since tooth 34 was in Nolla's stage 7.

\section{DISCUSSION}

One can inflict injuries to oneself owing to various activities like finger nail biting, bruxism, post-anaesthetic injury, to extreme self mutilation of oral mucosa. Theseinjuries may be, unintentional, premediated or habitual and may be due to a wide range of organic functional or behavioural etiologies. ${ }^{6}$

A radiograph plays a significant role in diagnosis, particularly if the foreign body is radiopaque. Various radiographic methods have been summarized by Hunter and Taljanovic to localize foreign objects such as vertex occlusal views, parallax views, triangulation techniques, tomography and stereo radiography. Metallic objects are radiopaque unless made of aluminium. ${ }^{7,8}$ In the present case it was accidental discovery with routine radiographic examination which was done to evaluate the carious lesion on the distal aspect of tooth 74. It hel ped in the exact location of the foreign object.
McCullock suggested that access to foreign object is improved by removing small amount of tooth structure. ${ }^{3} \mathrm{I}$ the present case since the needle was not clinically visible and it was lodged deep into the interdental area, extraction of the carious primary tooth was considered which showed more than $2 / 3^{\text {rd }}$ of distal root resorption which provided better visibility of the broken needle and thus permitted easy removal.

\section{CONCLUSION}

The clinical behaviour in patients who have had a penetrating injury is determined by the nature of the impacted foreign body. Removal of the foreign body becomes mandatory in most cases since they generally lead to secondary infection with abscess and eventually a formation of a fistula. Goldstein has reported a case of actinomycosis following placement of a jewellery chain pieceinto a maxillary central incisor. ${ }^{8}$ Apart from prevention of infection, it was necessary to remove the foreign body in this case as it was present interdentally and would interfere with achieving proper contact of the succedeneous teeth.

\section{REFERENCES}

1. J ayam C, Rao M, Bandlapalli A, Patel N. Self-injurious behaviour and foreign-body entrapment - Case Report. Ind J Den Sci 2013; 5(4):84-85.

2. Erdur B, Turkcuer I, Herken $\mathrm{H}$. A form of self-mutilation: tongue amputation with local anesthesia. AmJ Emerg Med 2006; 24(5):625-628.

3. Aduri R, Reddy RE, Kiran K. Foreign objects in teeth: retrieval and management. J Indian Soc Pedod Prev Dent 2009; 27(3):179-183.

4. Ahmed A, Chowdhary N, Mukunda KS, Kiran NK, Bansal A, Khan FA. Endodontic tragedy-retreival of an unusual foreign body- a case report. IOSR J Den Med Sci 2014; 13(10): 73-75.

5. MCauliffe N, Drage A, Hunter B. Staple diet: a foreign Body in a tooth. Int J Paed Dent 2005; 15:468-471.

6. Romer M, Dougherty N, Frutcher M. Alternative therapies in the treatment of oral self injurious behaviour. Alternative therapies in the treatment of oral self injurious behaviour: a case report. Spec Care Dentist 1998; 18(2):66-69.

7. Hunter TB, Taljanovic MS. Foreign bodies. Radiographics 2003; 23(3):731-757.

8. Goldstein BH, Scuibba J J , Laskin DM. Actinomycosis of the maxilla: A review of literature and a report case. J Oral Surg 1972; 30:362-366. 